\title{
A STUDY TO KNOW THE PATTERN OF PULMONARY FUNCTION IMPAIRMENTS IN CURED PULMONARY TUBERCULOSIS CASES
}

\author{
Brijesh Kumar1, Saurabh Agarwal2, Sanjay Kumar Verma³, Anand Kumar ${ }^{4}$
}

${ }^{1}$ Associate Professor, Department of Internal Medicine, GSVM Medical College, Kanpur.

${ }^{2}$ Assistant Professor, Department of Internal Medicine, GSVM Medical College, Kanpur.

${ }_{3}^{3}$ Associate Professor, Department of TB and Respiratory Diseases, Government Medical College, Kannauj, Uttar Pradesh.

${ }_{4}^{4}$ Associate Professor, Department of TB and Respiratory Diseases, GSVM Medical College, Kanpur.

\section{BACKGROUND}

ABSTRACT

India is the highest TB burden country in the world and patients with treated TB may remain lifelong sufferers of disabling sequelae. In cured pulmonary tuberculosis patients, many survivors develop into pulmonary sequelae that are characterized by bronchial and parenchymal structural changes, including bronchovascular distortion, bronchiectasis, emphysematous changes, and fibrotic bands. Structural changes lead to obstructive, restrictive, or mixed patterns of impaired pulmonary function.

Objective- This study was designed to analyse the pattern of pulmonary function abnormalities using spirometry with cured pulmonary tuberculosis (PTB) patients.

\section{MATERIALS AND METHODS}

This was a cross sectional study conducted in a department of internal medicine \& department of respiratory diseases, GSVM Medical College, Kanpur (India), from January 2017 to July 2017. The patients of old treated pulmonary tuberculosis, presented with complaint of dyspnoea, were picked up from out-patient and in-patients section of the hospital at random. These patients were further divided into group A and group B.

\section{RESULTS}

Seventy-eight patients with cured pulmonary tuberculosis were enrolled during the study period. There were 53 males (67.9\%) and 25 (32\%) females. The mean age among males and females study population were 46.5 and 41.5 years respectively. The mean duration of anti-tuberculosis treatment was 12.5 months (range: 6-38 Months). Dyspnoea was associated in all the cases. Majority of the patients in both groups, belongs to MMRC grade $2 \& 3$. The airflow obstruction was found in $50 \%$, followed by mixed defect $(37.1 \%)$ and restriction in $12.8 \%$ cases.

\section{CONCLUSION}

The present study highlighted that most common pulmonary impairments were obstruction, followed by mixed and restrictive pattern.

\section{KEYWORDS}

Cured, Pulmonary Tuberculosis, Airflow Obstruction, Mixed Pattern, Restriction.

HOW TO CITE THIS ARTICLE: Kumar B, Agarwal S, Verma SK, et al. A study to know the pattern of pulmonary function impairments in cured pulmonary tuberculosis cases. J. Evolution Med. Dent. Sci. 2018;7(09):1139-1143, DOI: $10.14260 /$ jemds/2018/259

\section{BACKGROUND}

Tuberculosis (TB) is among the top infectious causes of death worldwide. ${ }^{1}$ India accounts for one fourth of the global TB burden. In 2015, an estimated 28 lakh cases occurred, and 4.8 lakh people died due to TB. The incidence of TB has reduced from 289 per lakh per year in 2000 to 217 per lakh per year in 2015 and the mortality due to TB has reduced from 56 per lac per year in 2000 to 36 per lac per year in $2015 .^{2}$

In patients infected with M. tuberculosis, whether treated or untreated, a variety of pulmonary and extrapulmonary sequelae and complications can occur, categorized as follows: parenchymal lesions, which include tuberculoma, thin-walled 'Financial or Other Competing Interest': None.

Submission 29-12-2017, Peer Review 08-02-2018,

Acceptance 14-02-2018, Published 26-02-2018.

Corresponding Author:

Dr. Saurabh Agarwal,

Assistant Professor,

Department of Internal Medicine,

GSVM Medical College, Kanpur, India.

E-mail: dragarwalsaurabh@gmail.com

DOI: $10.14260 /$ jemds $/ 2018 / 259$ stenosis, and broncholithiasis. ${ }^{3}$ Structural changes lead to obstructive, restrictive, or mixed patterns of impaired pulmonary function. ${ }^{4-9}$ Studies in patients with pulmonary tuberculosis (PTB) have demonstrated that 33.3-94.0\% of such patients develop impaired pulmonary function. 3,10

Pulmonary function test (PFT), objectively quantify lung function and impairment and are used to evaluate persons with chronic lung disease.11-12 The present study was done to determine the pattern of pulmonary function impairments in patients with cured pulmonary tuberculosis cases, presented with respiratory complaints.

\section{MATERIALS \& METHODS}

This was a cross sectional study conducted in a department of internal medicine \& department of respiratory diseases, GSVM Medical College, Kanpur (India). The patients of cured PTB were picked up from inpatients section and out-patient section of the hospital and consecutive sampling method were used. Seventy-eight consecutive patients with a history of past pulmonary tuberculosis and who has taken full course 
of anti-tuberculosis treatment and presented with respiratory complaints, from January 2017 to July 2017, were enrolled. Then patients were further divided into 2 groups, namely group A and group B. Group A, patients who have taken one-time ATT for 6-8 months durations and group B patients who have taken ATT, for more than 8 months duration. Informed consent was taken from all patients. The study was approved by the Ethics committee.

A detailed history was taken and physical examination was carried out for every subject who entered the study as per the pre-designed proforma. Patients were examined clinically and radiologically with a view to establish diagnosis. Haemoglobin, Total Leucocyte Count (TLC), Differential Leucocyte Count(DLC), Fasting and Postprandial Blood Sugar, Serum Creatinine, SGPT, Serum Bilirubin, Serum Protein, Serum Albumin and Sputum for AFB. Body Mass Index (BMI) $(\mathrm{kg} / \mathrm{m} 2)$ of each patient was calculated by measuring weight and height. Dyspnoea was assessed by using the modified British Medical Research Council (mMRC) dyspnoea scale.

Subsequently, routine spirometry was performed as per the recent ATS guidelines. Calibration was done daily before use ${ }^{11-12}$. Pulmonary function tests were performed by trained technicians with the patients in sitting postures. Each patient performed at least three acceptable forced expiratory manoeuvres, which fulfilled the criteria of repeatability.

\section{Statistical Analysis}

Data was compiled using Microsoft excel and analysed using SPSS, statistics version 20.0. Data was statistically described in terms of mean \pm SD and range, or frequencies (number of cases), when appropriate. Categorical variables were analysed using percentage and chi square test. Categorical Vs Continuous variables were analysed using mean, standard deviation and t test and $p$ value less than 0.05 was considered significant.

\section{RESULTS}

A Total of 118 patients with prior history of pulmonary tuberculosis, who attended OPD with respiratory diseases within the study period, were enrolled. 14 patients were excluded as they had active pulmonary tuberculosis. 24 more patients were excluded based on our exclusion criteria $(2 \mathrm{had}$ HIV, 12 had prior history of inadequately treated TB, 10 had respiratory disease prior to having TB). Spirometric evaluation was done in 80 patients and out of them, 2 were excluded as their spirometry did not meet acceptability and reproducibility criteria even after repeated attempts. Therefore, a total of 78 patients were selected for final analysis. The mean age among male and female study population were 46.5 and 41.5 years respectively. Details of the baseline characteristics of the study population has been provided in (table: 1 ).

In group $\mathrm{A}$, the percentages of males and females were $66.6 \%$ and $33.3 \%$ respectively. While, in group B, the percentages of males and females were $64.2 \%$ and $30.9 \%$ respectively. The percentages of smokers in group A and group B, were $33.3 \%$ and $30.9 \%$, respectively. The percentages of cough, dyspnoea, haemoptysis, fever and chest pain were, $50 \%, 100 \%, 16.6 \%, 22.2 \%$ and $11.1 \%$ respectively. While, in Group B, The percentages of cough, dyspnoea, haemoptysis, , fever and chest pain were, $61.9 \%$,
$100 \%, 33.3 \%, 28.5 \%$ and $19 \%$ respectively. The majority of patients in both groups, belong to MMRC grade $2 \& 3$. (The details of other parameters are given in table: $2 \& 3$ ).

\begin{tabular}{|c|c|c|}
\hline Sl. No. & Parameter & \\
\hline 1 & $\begin{array}{l}\text { Mean age in years } \\
\text { (Mean } \pm \text { SD) }\end{array}$ & $\begin{array}{c}44.4 \pm 10.24 \text { Years } \\
\text { (Range, } 22-75 \text { ) }\end{array}$ \\
\hline 2 & Mean BMI & $19.35 \pm 2.95(13.2-28.3)$ \\
\hline 3 & Mean Smoking Index & 308.7 \\
\hline 4 & Mean PY & 15.48 \\
\hline 5 & $\begin{array}{l}\text { Mean duration of anti- } \\
\text { tuberculosis treatment } \\
\text { (in months) }\end{array}$ & $\begin{array}{c}12.5 \pm 6.48 \text { Months } \\
\text { (R-6-38 Months) }\end{array}$ \\
\hline 6 & $\begin{array}{c}\text { Mean durations of COPD } \\
\text { symptoms (in years) }\end{array}$ & $\begin{array}{c}6 \pm 3.37 \text { years } \\
\text { (4 months-16 years) }\end{array}$ \\
\hline 7 & Mean FEV1/FVC & $60.35 \pm 11.6$ \\
\hline 8 & Mean FEV1 & $46.37 \pm 11.8$ \\
\hline 9 & Mean FVC & $60.76 \pm 11.8$ \\
\hline
\end{tabular}

\begin{tabular}{|c|c|c|c|c|c|c|}
\hline $\begin{array}{l}\dot{\Sigma} \\
\dot{\pi}\end{array}$ & \multicolumn{2}{|c|}{ 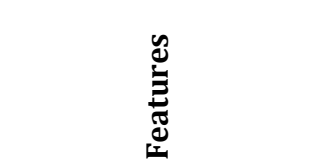 } & 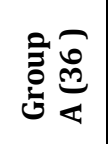 & 옳 & $\partial^{0}$ & $\begin{array}{l}0 \\
\frac{0}{\pi} \\
2 \\
0\end{array}$ \\
\hline \multirow{2}{*}{1} & \multirow{2}{*}{$\begin{array}{c}\text { Age } \\
(\text { Mean } \pm \text { SD })\end{array}$} & Males & \begin{tabular}{|c|}
$46 \pm$ \\
10.41
\end{tabular} & $\begin{array}{c}45.5 \pm 1 \\
0.96\end{array}$ & & 0.837 \\
\hline & & Females & $\begin{array}{c}39.8 \pm \\
7.87 \\
\end{array}$ & $\begin{array}{l}43 \pm \\
9.86\end{array}$ & & 0.123 \\
\hline \multirow{2}{*}{2} & \multirow[t]{2}{*}{ Sex } & Males & 24 & 29 & & \multirow{2}{*}{0.822} \\
\hline & & \begin{tabular}{|l|} 
Females \\
\end{tabular} & 12 & 13 & & \\
\hline 3 & \multicolumn{2}{|c|}{ BMI } & $\begin{array}{c}18.93 \pm \\
2.95 \\
\end{array}$ & $\begin{array}{c}19.7 \pm 2 . \\
95\end{array}$ & & 0.228 \\
\hline \multirow[b]{2}{*}{4} & \multirow{2}{*}{ Smoking } & Smokers & 16 & 13 & 37.2 & \multirow[b]{2}{*}{0.219} \\
\hline & & $\begin{array}{c}\text { Non- } \\
\text { smokers }\end{array}$ & 20 & 29 & 62.8 & \\
\hline \multirow{5}{*}{5} & \multirow{5}{*}{$\begin{array}{c}\text { Clinical } \\
\text { symptoms }\end{array}$} & $\begin{array}{l}\text { Cough } \\
\text { with } \\
\text { expect- } \\
\text { oration }\end{array}$ & 18 & 26 & 56.4 & 0.291 \\
\hline & & Dyspnoea & 36 & 42 & 100 & 0.110 \\
\hline & & $\begin{array}{c}\text { Haemopty } \\
\text { sis }\end{array}$ & 6 & 14 & 25.6 & 0.091 \\
\hline & & \begin{tabular}{|l|} 
fever \\
\end{tabular} & 8 & 12 & 25.6 & 0.522 \\
\hline & & $\begin{array}{l}\text { Chest } \\
\text { pain }\end{array}$ & 4 & 8 & 15.4 & 0.333 \\
\hline \multirow{4}{*}{6} & \multirow{4}{*}{$\begin{array}{c}\text { MMRC } \\
\text { Dyspnoea } \\
\text { Grade }\end{array}$} & I & 0 & 0 & & \multirow{4}{*}{0.834} \\
\hline & & II & 16 & 15 & 39.7 & \\
\hline & & III & 18 & 23 & 52.6 & \\
\hline & & IV & 2 & 4 & 7.7 & \\
\hline \multirow{3}{*}{7} & \multirow{3}{*}{$\begin{array}{l}\text { Spirometry } \\
\text { Impairment }\end{array}$} & $\begin{array}{c}\text { Obstructi } \\
\text { on }\end{array}$ & 22 & 17 & 50 & \multirow{3}{*}{0.175} \\
\hline & & \begin{tabular}{|c|} 
Restrictio \\
$\mathrm{n}$
\end{tabular} & 3 & 7 & 12.8 & \\
\hline & & Mixed & 11 & 18 & 37.2 & \\
\hline 8 & \multicolumn{2}{|c|}{$\begin{array}{l}\text { Duration of ATT } \\
\text { (In months) }\end{array}$} & 7.97 & 17.45 & & \\
\hline & \multicolumn{6}{|c|}{ Table 2. Comparison between Group A and Group B } \\
\hline
\end{tabular}




\begin{tabular}{|c|c|c|c|c|c|c|c|}
\hline \multirow[b]{2}{*}{$\begin{array}{l}\dot{0} \\
z \\
\dot{n}\end{array}$} & & \multicolumn{3}{|c|}{ Group A (N=36) } & \multicolumn{3}{|c|}{ Group B (N=42) } \\
\hline & & 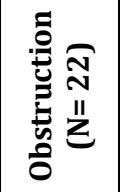 & 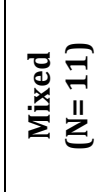 & 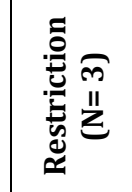 & 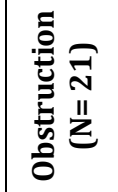 & 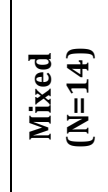 & 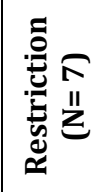 \\
\hline 1 & $\begin{array}{c}\text { FEV1/ } \\
\text { FVC } \\
\text { (Mean } \\
\pm \text { SD) }\end{array}$ & $\begin{array}{c}59.2 \pm \\
5.21\end{array}$ & $\begin{array}{c}52.2 \pm \\
7.97\end{array}$ & $\begin{array}{c}81.33 \pm 5 \\
10\end{array}$ & $\begin{array}{c}60.17 \pm \\
4.36\end{array}$ & $\begin{array}{c}53.76 \pm \\
9.21\end{array}$ & $\begin{array}{c}85.2 \pm \\
7.34\end{array}$ \\
\hline 2 & $\begin{array}{c}\text { FEV1 } \\
\text { (Mean } \\
\pm \text { SD) }\end{array}$ & $\begin{array}{c}47.31 \pm \\
8.95\end{array}$ & $\begin{array}{c}34.36 \pm \\
12.61\end{array}$ & $\begin{array}{c}56.66 \pm \\
8.08\end{array}$ & $\begin{array}{c}50.47 \pm \\
5.47\end{array}$ & $\begin{array}{c}42.27 \pm \\
10.65\end{array}$ & $\begin{array}{c}58.42 \pm \\
15.33\end{array}$ \\
\hline 3 & $\begin{array}{c}\text { FVC } \\
\text { (Mean } \\
\pm \text { SD) }\end{array}$ & $\begin{array}{c}68.68 \pm 1 \\
0.6\end{array}$ & $\begin{array}{c}45 \pm 11 . \\
75\end{array}$ & $52 \pm 7.21$ & $\begin{array}{c}72.9 \pm 1 \\
71\end{array}$ & $\begin{array}{c}52.77 \pm \\
8.57\end{array}$ & $\begin{array}{c}50.57 \pm \\
10.5\end{array}$ \\
\hline
\end{tabular}

\section{DISCUSSION}

Patients with treated TB may remain lifelong sufferers of disabling sequelae of the disease which subsequently impair their quality of life. The commonly observed complications are lung scarring (fibrosis), bronchiectasis, Chronic Pulmonary Aspergillosis (CPA), air way stenosis and Chronic Obstructive Pulmonary Disease (COPD) and it may even be a risk factor for lung cancer.13-14 Neeta Singh et al had done a study on 51 multidrug resistant TB patients who were successful treated. Of these, $78 \%$ had persistent respiratory symptoms, $98 \%$ had residual radiological sequelae, $96 \%$ had ventilatory defects with $66 \%$ of those with ventilatory defects exhibiting a mixed type of ventilatory abnormality while $19 \%$ had pure restriction and $11 \%$ had pure obstruction after completion of treatment 15 . In a similar small prospective study among 25 patients with drug susceptible TB, the investigators observed resolution of exudative lesions and adenopathy at completion of treatment while leaving permanent features that included emphysematous change (36\%), bronchiectasis $(40 \%)$, bronchovascular distortion (56\%), and fibrotic bands (64\%).

Studies with longer follow-up have revealed that a large percentage of patients with treated pulmonary tuberculosis show signs of permanent airflow obstruction or restrictive impairment.7,9,16-17 Post tuberculosis pulmonary impairment, therefore has emerged as a distinct clinical entity. ${ }^{18-19}$ The spirometry pattern in present study reveals, obstruction, mixed pattern and restriction in $50 \%, 37.1 \%$ and $12.8 \%$ respectively. These findings indicate a huge burden of post treatment pulmonary function abnormalities in patients with pulmonary tuberculosis.

Manji $\mathrm{M}$ et al done a cross sectional study among 501 patients with PTB, who had completed atleast 20 weeks of treatment. They reported that the overall prevalence of lung function abnormalities among $74 \%$ cases and majority was due to obstruction (42\%) followed by mixed (19\%) and restrictive $(13 \%)$ abnormalities. ${ }^{20}$ Our study results are comparable to above mentioned study.

Saini LK et al done a study among 80 patients of old PTB and they reported that commonest pattern was mixed, followed by obstruction. ${ }^{21}$ Chuskin MI et al done a study to evaluate the prevalence of pulmonary function abnormalities in, 214 consecutive patients treated for pulmonary tuberculosis. They reported that PFT results were normal in
$52.4 \%$ patients. Pulmonary impairment was identified in $47.7 \%$ of the patients, the pattern being obstructive in $34.6 \%$, restrictive in $8.4 \%$, mixed in $3.7 \%$, and nonspecific in $0.9 \% .{ }^{22}$ The percentage of obstruction and mixed pattern in present study are $50 \%$ and $10.3 \%$ respectively. Santra A et al done a study to evaluate the pulmonary function by spirometry among 198, post-tuberculosis cases. They reported, normal spirometry in $11.1 \%$, purely obstructive abnormality in 19.1 $\%$ and obstructive airway disease in $69.7 \%$ cases. $^{23}$ Nihues S de $\mathrm{S}$, et al done a cross-sectional study in 120 , cured tuberculosis individuals from 2002 to 2012. They further reported that forty-one percent $(95 \% \mathrm{CI}, 29-56)$ had pulmonary disorders, of which the most prevalent were obstructive disorders (49\%), followed by obstructive disorder with reduced forced vital capacity disorders (46\%) and restrictive disorders (5\%). ${ }^{24}$ Baig IM et al done a study to determine the frequency of chronic obstructive pulmonary disease (COPD) as a sequel of treated pulmonary tuberculosis in 47 cases. They reported that $55.3 \%(n=26)$ were found to have an obstructive ventilatory defect and fourteen (29.9\%) were found to have a restrictive pattern in their spirometry and $7(14.8 \%)$ revealed a mixed obstructive and restrictive pattern. ${ }^{25}$ Zakaria MW et al done a study to detect the prevalence of chronic obstructive pulmonary disease (COPD) as a sequel of treated pulmonary tuberculosis (PTB) among 50 patients. They reported that Pulmonary function testing showed 22 patients (44\%) with irreversible obstructive pattern, seven patients had restrictive ventilatory defect, and three patients had mixed obstructive and restrictive pattern. ${ }^{26}$ In a study by Pasipanodya et al. (2007) in the USA, the prevalence of abnormal lung function of any type was 59 $\%$ and the prevalence of individual subtypes of impairment for obstructive, restrictive and mixed were 15, 31 and $13 \%$ respectively. 27 On comparison, the results of present study is on higher side. Bemba ELP et al done a cross-sectional study that included 150 patients with previous pulmonary tuberculosis. Among spirometry, they have reported restrictive pattern, obstructive pattern and mixed pattern in $74.76 \%, 9.71 \%$ and $15.53 \%$ respectively. 28

SK Verma et al had a conducted a study in Indian population to find out spirometric abnormality in post pulmonary tuberculosis patients and found that out of 92 patients 36 (39.1\%) patients had obstructive airway disease by spirometry criteria of which 7 (7.6\%) had reversible phenomena and $29(31.5 \%)$ had irreversible phenomena. 37 $(40.2 \%)$ had restrictive pathology and a normal spirometry was seen in 9 (9.7\%) patient. ${ }^{29}$ Santosh Kumar et al conducted a study in 82 patients of post pulmonary tuberculosis to know the factors associated with the spirometric abnormalities. They reported that Spirometry revealed obstructive pattern in $45.1 \%$, restrictive pattern in $25.6 \%$ and normal results in $29.3 \% .^{30}$

The development and subsequent disease progression seen in TB result in characteristic destructive parenchymal lung changes due to the destruction of the pulmonary extracellular matrix (ECM). ${ }^{31}$ In particular, the role of matrix metalloproteinases (MMPs) deserves special mention. MMPs are a family of naturally occurring protease enzymes capable of degrading the ECM. In conditions where there is altered or unregulated activity of MMP enzymes, there exists the potential for re-modelling and subsequent damage to the lung architecture. The antigenic wall component of 
mycobacterium tuberculosis, lipoarabinomannan (LAM), stimulates the release of MMP-9 as well as up regulating genetic expression of MMP-1 and MMP-9. This results in the breakdown of collagen in the ECM and also stimulates further lung damage by activation Interleukin- 8 and other cytokines. This process may be central to the development of cavitatory parenchymal lung damage. 32

\section{CONCLUSION}

The most common pulmonary impairment observed in present study was obstruction pattern. Therefore, tuberculosis imposes an infectious and noninfectious burden to the healthcare infrastructure and the infectious and microbiologic domain has received much attention in TB treatment, while a lot is still left to be desired in the noninfectious sequela. So, the findings of this study warrant an early detection of these abnormalities to improve the quality of life of among TB patients.

\section{REFERENCES}

[1] WHO. The Global Burden of Disease 2016 Update. 2016.

[2] Revised National Tuberculosis Control Programme. Annual status report of India. 2017. www.tbcindia.gov.in.

[3] Kim HY, Song KS, Goo JM, et al. Thoracic sequelae and complications of tuberculosis. Radiographics 2001;21(4):839-58.

[4] Long R, Maycher B, Dhar A, et al. Pulmonary tuberculosis treated with directly observed therapy: serial changes in lung structure and function. Chest 1998;113(4):933-43.

[5] Gaensler EA, Lindgren I. Chronic bronchitis as an etiologic factor in obstructive emphysema, preliminary report. Am Rev Respir Dis 1959;80(1 Pt 2):185-93.

[6] Snider GL, Doctor L, Demas TA, et al. Obstructive airways disease in patients with treated pulmonary tuberculosis. Am Rev Respir Dis 1971;103(5):625-40.

[7] Wilcox PA, Ferguson AD. Chronic obstructive airways disease following treated pulmonary tuberculosis. Respir Med 1989;83(3):195-8.

[8] Weiner H. Changes in employment status associated with hospitalization for tuberculosis. I. Analysis of 163 consecutively admitted males. Am Rev Respir Dis 1963;87:17-22.

[9] Hnizdo E, Singh T, Churchyard G. Chronic pulmonary function impairment caused by initial and recurrent pulmonary tuberculosis following treatment. Thorax 2000;55(1):32-8.

[10] Stepanian IE. Bronchial impotence in patients with pulmonary tuberculosis. Tuberk Biolezni Legkih 2013;4(1):6-11.

[11] Miller MR, Hankinson J, Brusasco V, et al. Standardisation of spirometry. Eur Respir J 2005;26(2):319-38.

[12] Wanger J, Clausen JL, Coates A, et al. Standardisation of the measurement of lung volumes. Eur Respir J 2005;26(3):511-22.

[13] Shah M, Reed C. Complications of tuberculosis. Curr Opin Infect Dis 2014;27(5):403-10.
[14] Liang HY, Li XL, Yu XS, et al. Facts and Fiction of the relationship between pre-existing tuberculosis and lung cancer risk: a systematic review. Int J Cancer 2009;125(12):2936-44.

[15] Singla N, Singla R, Fernandes S, et al. Post treatment sequelae of multi-drug resistant tuberculosis patients. Indian J Tuberc 2009;56(4):206-12.

[16] Krishna K, Bond S, Artvinli M, et al. Pulmonary function in treated tuberculosis: a long-term followup. Am Rev Respir Dis 1977;115:402-4.

[17] Vargha G. Fifteen year follow-up of lung function in obstructive and non-obstructive pulmonary tuberculosis. Acta Med Hung 1983;40(4):271-6.

[18] Leitch AG. Pulmonary tuberculosis: clinical features. In: Seaton A, Seaton D, Leitch AG. eds. Crofton and Douglass's Respiratory disease. United Kingdom: Blackwell Science 2002: p. 523.

[19] Singh B, Chaudhary 0. Trends of pulmonary impairment in persons with treated pulmonary tuberculosis. Int J Med Res Prof 2015;1(1):8-11.

[20] Manji M, Shayo G, Mamuya S, et al. Lung functions among patients with pulmonary tuberculosis in Dar es salaam-a cross sectional study. BMC Pulmonary Medicine 2016;16:58.

[21] Soni LK, Borana H, Purohit G. Impact of pulmonary tuberculosis sequelae on the functional status. Indian Journal of Immunology and Respiratory Medicine 2016;1(4):97-9.

[22] Chuskin MI, Ots ON. Impaired pulmonary function after treatment for tuberculosis: The end of the disease? J Bras Pneumol 2017;43(1):38-43.

[23] Santra A, Dutta P, Manjhi R, et al. Clinico-radiologic and spirometric profile of an Indian population with post-tuberculous obstructive airway disease. Journal of Clinical and Diagnostic Research 2017;11(3):0C350C8.

[24] Sde NS, Mancuzo EV, Sulmonetti N, et al. Chronic symptoms and pulmonary dysfunction in posttuberculosis Brazilian patients. Braz J Infect Dis 2015;19(5):492-7.

[25] Baig IM, Saeed W, Khalil KF. Post tuberculosis chronic obstructive pulmonary disease. J College of Physician and Surgeons Pakistan 2010;20(8):542-4.

[26] Zakaria MW, Moussa HA. Chronic obstructive pulmonary disease in treated pulmonary tuberculosis patients. Egyptian J Bronchology 2015;9(1):10-13.

[27] Pasipanodya JG, Miller TL, Vecino M, et al. Pulmonary impairment after tuberculosis. Chest 2007;131(6):1817-24.

[28] Bemba ELP, Moyikoua R, Ouedraogo AR, et al. Spirometric and radiographic profile of patients with pulmonary tuberculosis treated and cured at the Department of Pulmonology of Brazzaville University Hospital. Rev Pneumol Clin 2017;73(5):217-24.

[29] Verma SK, Narayan KV, Kumar S. A study on prevalence of obstructive airway disease among post pulmonary tuberculosis patients. Pulmon 2009;11(1):4-7.

[30] Kumar SPV, Lisha PV. Evaluation of pulmonary impairment by spirometry in post pulmonary tuberculosis patients. JMSCR 2017;5(5):21745-51. 
[31] Elkington PT, Emerson JE, Lopez-Pascua LD, et al. Mycobacterium tuberculosis up-regulates matrix metalloproteinase-1 secretion from human airway epithelial cells via a p38 MAPK switch. J Immunol 2005;175(8):5333-40.
[32] Elkington PT, Friedland JS. Matrix metalloproteinases in destructive pulmonary pathology. Thorax 2006;61(3):259-66. 